to extremely low concentrations and the hypomethioninaemia persisted for several days (unpublished observation). A possible explanation for this unexpected result lies in the fact that methionine metabolism is influenced, and in opposite directions, by both methylcobalamin and by adenosylcobalamin, the former through the methionine synthetase reaction which increases the serum methionine. The latter is a coenzyme in the methylmalonyl-CoA mutase reaction; this is the last reaction in the propionyl-CoA-succinyl CoA pathway along which methionine is catabolised to the citric acid cycle. Adenosylcobalamin, therefore, aids the catabolism of methionine and depresses its concentration in serum. The above findings suggest that adenosylcobalamin alone is active and that the action of methylcobalamin is not expressed, and the methionine synthetase reaction therefore not activated by these very minute doses of vitamin $B_{12}$. They do, however, invariably produce a reticulocyte response, often a very brisk one, which again suggests that vitamin $B_{12}$ has an erythropoietic action which is independent of the methionine synthetase reaction, and by inference, from both the methylfolate trap and the formate starvation hypothesis, in the absence of the thymidylate synthetase action as well.

Unfortunately by the time the possible importance of these results was realised the work could not be repeated. If, however, the above interpretation is correct it would probably take several days for these very small doses of vitamin $B_{12}$ to correct the $d U$ suppression test. This contention could therefore readily be tested by relating this interval to the daily reticulocyte count following a daily dose of $2 \mu \mathrm{g}$ of vitamin $\mathrm{B}_{12}$ in pernicious anaemia. A clear reticulocyte response, not necessarily the peak, occurring before the $\mathrm{dU}$ test is corrected would lend it support.

T E PARRY Awelon, Pen-y-Turnpike, South Glamorgan CF6 4 HG

1 Chanerin I, Deacon R, Lumb M, Perry J Cobalamin and Folate, recent developments. f Clin Pathol 1992;45:277-83.

2 Ganeshaguru K, Hoffbrand AV. The effect of deoxyuridine, vitamin $B_{12}$ folate and alcohol
on the uptake of thymidine and on the on the uptake of thymidine and on the
deoxymucleoside triphosphate concentration in normal and megaloblastic cells. $\mathrm{Br} \mathcal{F}$ of in normal and megalobl

3 Hans HA, Weinfeld A. Metabolite effect and diagnostic value of small doses of folic acid and vitamin $B_{12}$ in megaloblastic anaemia. Acta Medica Scandinavia 1962; 172:427-42.

4 Chanarin I. Megaloblastic anaemia. Clin Hae matol 1976;5:754.

5 Parry TE. Serum valine and methionine levels in pernicious anaemia under treatment. $\mathrm{Br} f$ Haematol 1969;16:271-9.

\section{Risk of inhaling cyanide during necropsy examination}

I read with interest the article by Forrest, Galloway, and Slater on the risk of inhaling cyanide during necropsy on cases of cyanide poisoning.' There is, admittedly, a theoretical risk of inhaling a large amount of cyanide, as observed by Andrews et al. ${ }^{2}$

The recommendation that a respirator be worn during the necropsy or that the stomach should be opened in a fume cabinet is commendable but suffers from one draw- back. In one of my cases the diagnosis of cyanide poisoning was made only after opening the stomach. ${ }^{3}$ This case presented as a sudden natural death and my diagnosis of cyanide poisoning, based solely on the smell, was greeted with considerable disbelief by the investigating police officers. Subsequent investigations led to the discovery of a suicide note and an empty container but the impression of everybody concerned, including myself, was that of sudden natural death. At least I am fortunate that I can smell cyanide (My colleague at that time has never been able to).

Theoretically, then, a pathologist who could not smell cyanide would inhale potentially dangerous amounts of cyanide during such a necropsy. Should pathologists routinely wear respirators when performing any necropsy where the circumstances of death are not clear? Or should they routinely open the stomach in a fume cabinet in all such cases? When we refer to the changing face of pathology is it because pathologists of the future will be wearing gas masks? Perhaps readers should be told.

\section{G C A FERNANDO Central Pathology Laboratory Histopathology Department, North Staffordshire Hospital Centre Hartshill, Stoke on Trent ST4 7PA}

1 Forrest ARW, Galloway JH, Slater DN. The cyanide poisoning necropsy: An appraisal of risk factors. I Clin Pathol 1992;45:544-5.

2 Andrews JM, Sweeney ES, Grey TC, Wetzel T.

The biohazard potential of cyanide poisoning during post-mortem examination. $\mathcal{f}$ For $S_{c i}$ 1989;34:1280-4.

3 Fernando GCA, Busuttil A. Cyanide ingestioncase studies of four suicides. Am $\mathcal{f}$ Forens Med Pathol 1991;12:241-6.

\section{Drs Forrest, Galloway, and Slater comment:}

We are confident that either common sense or natural selection would prevail in the situation Dr Fernando describes. Pathologists will make a sensible judgement of the risks in a particular case and the precautions that reasonably ought to be taken in the light of all the circumstances, including their knowledge of their own olfactory capabilities.

\section{Glove puncture in the post mortem room}

I cannot allow Drs Weston and Locker's comments on my criticism of their paper to go unchallenged. They have not correctly cited the paper of Hall et al.' This study involved 664 technicians (588 anatomical pathology technicians and 76 mortuary technicians), not 76 as they claim, plus 774 consultants. It also included a control group of Coroner's officers. Two cases of hepatitis B were indeed reported as Drs Weston and Locker state. However, one of these was in a Coroner's officer and therefore unlikely to be due to unnoticed glove puncture! The incidence in the at risk and control groups was therefore equal. The one reported case of tuberculosis is almost certainly unrelated to glove puncture. The discussion at the end of the paper concludes that apart from the expected high rates of respiratory disorders, the digestive and infectious disease excess noted in the technicians was similar to the findings of a large scale survey of medical laboratory workers. I would therefore reiterate my conclusion that unnoticed glove puncture is not in itself a health hazard. Laceration of the skin is undoubtedly a health hazard but is not likely to be affected by more frequent glove changes. I agree with the other correspondents that the efforts to minimise the risk of blood born infection in the post mortem room would be better directed towards reducing that hazard. I have found that the available chain mail protective overgloves for the left hand are of great value in this respect.

$$
\begin{array}{r}
\text { P J DUNN } \\
\text { Department of Pathology, } \\
\text { Royal Infirmary, } \\
\text { Castle Street, } \\
\text { Worcester WRI } 3 A S
\end{array}
$$

1 Hall AJ, Aw TL, Harrington JM. Morbidity survey of post mortem room staff. $\mathcal{f}$ Clin Pathol 1991;44:433-5.

c-erb-B-2 expression in male breast carcinoma

Fox et al recently reported a complete lack of c-erb-B-2 expression in 21 cases of male breast carcinoma, ${ }^{1}$ while Wright et al reported overexpression in a single case. ${ }^{2}$ We have so far examined 33 cases of male breast carcinoma for c-erb-B-2 expression using the monoclonal antibody NCL-CB11 (Novocastra) and a standard immunoperoxidase technique. Omission of the primary antibody and a known positive case of female breas carcinoma were used as negative and positive controls, respectively. Membrane staining was completely absent in 20 cases, but positive membrane staining was present focally within the tumour in 12 cases and throughout the tumour in one case. Thus $39 \%$ of our cases show evidence of c-erb-B-2 overexpression. This figure is similar to the $35 \%$ reported by Gattuso et $a l^{3}$ in their series of 26 cases.

Our results show that a proportion of male breast carcinomas are associated with c-erbB-2 overexpression, which is usually related to gene amplification. However, it remains to be seen whether this has the same prognostic importance as that seen in female breast carcinomas.

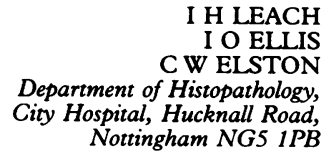

Fox SB, Day CA, Rogers S. Lack of $c-e r b-B-2$ oncoprotein expression in male breast carcinoma. I Clin Pathol 1991;44:960-1.

2 Wright C, Prasad K, Lennard TJW. erbB2 expression in breast and other human mours. F CIin Pathol 1992;45:459-60.

3 Gattuso P, Reddy V, Green L, Castelli M, Wick $M$. "New" prognostic factors in invasive M. "New" prognostic factors in invasive
breast cancer in men. Mod Pathol 1992;5: 13A.

\section{The teaching of death certification}

Death certificates are usually issued by preregistration house officers, often badly, and sometimes with only a mode of death as opposed to the disease producing death.' 
Although the Office of Population Censuses and Surveys states that these should not be accepted by the Registrar of Births and Deaths, they often are. Among their other values, hospital post mortem examinations provide a setting where death certification is discussed and pathologists can instruct clinicians on this subject. The falling necropsyrate, reaching $5 \%$ in our hospital, suggests that inaccuracies in death certification will become commoner, increasing the need for formal undergraduate teaching of this subject. Accordingly, we contacted all undergraduate pathology departments in England and Wales and asked them if death certification featured in their curriculum. Most already teach this subject, usually as part of forensic medicine. However, three of 19 respondents indicated that no such teaching was given. With the declining necropsy rate, the opportunities to redress this deficiency will decline. We suggest that all undergraduate pathology departments examine their teaching of death certification and if necessary introduce it, as requested, some years ago by the Registrar General.

$S$ A KELLY

E GRADWELI

Department of Pathology, St Helens and Knowsley Hospitals Trust, Prescot, Merseyside L35 5DR

1 Leadbetter S, Knight B. Anomalies and ambiguities in the disposal of the dead. $\mathcal{F}$ Roy Coll Phys Lond 1986;20:273-5.

\section{BOOK REVIEWS}

All titles reviewed here are available from the BMJ Bookshop, PO Box 295, London WC1H 9TE. Prices include postage in the United Kingdom and for members of the British Forces Overseas, but overseas customers should add $£ 2$ per item for postage and packing. Payment can be made by cheque in sterling drawn on a United Kingdom bank, or by credit card (Mastercard, VISA or American Express) stating card number, expiry date, and your full name.

The Health of the Nation. The BMJ View. Ed Richard Smith. (Pp 237; soft cover UK $£ 9.95$; Overseas $£ 12.00$.) British Medical Association. 1991. ISBN 0727903144

Unfettered by having studied the United Kingdom government Green Paper that provoked this book, I was able to try, like a literary retrovirus, mentally to recreate the original based on the 28 critiques before me. The articles in question all originally appeared in the British Medical fournal.

Essentially it seems that the government is promulgating a hotch-potch of health care targets, called a strategy, and that the initiative gets no, one, or two cheers depending on your point of view. The Radical Statistics Health Group kicks off by giving the whole thing a bit of a thumbs down. It points out (very reasonably) that one should be clear about the difference between a plan for improving the NHS and a plan for improving the nation's health, and opines that the Green Paper is muddled on this point. The Group is followed by eminent experts in several clinical, political, and management fields who give their various views about what is missing from the consultative document and what would be done if they had their way, most of which is pretty predictable.

What can be said of the whole? On the positive side it is interesting, easy to read, and a good source of quotable health care statistics with which to amaze and fascinate your friends. On the negative side, despite the subtitle, it has no cohesive viewpoint and tends to meander. It is also rather sobering in some ways. For me it generated the worrying but irrepressible image of a population of well nourished, well housed, financially secure centenarians gently degenerating without specific disease. Is that utopia?

J S LILLEYMAN

Gastrointestinal Pathology and its Clinical Implications. Vols I and II. K J Lewin, R H Riddell, W M Weinstein. (Pp 1395; \$295.) Igaku-Shoin Medical Publishers, Inc. 1992. ISBN 0-89640-153-7

Gastroenterology has always derived particular benefit from close cooperation between clinicians and pathologists. This important theme is meticulously explored in this impressive two volume book which brings together a vast amount of updated clinical and pathological data relating to the gastrointestinal tract, including the oesophagus. The well organised text is embellished by numerous illustrations almost exclusively in colour as well as many well constructed tables. The cooperative theme is further developed by a series of perceptive recommendations to pathologists faced with the interpretation of gastrointestinal biopsy specimens and also by illustrative case reports. The authors have not refrained from expressing personal views, which, although at times controversial, are certainly stimulating and informative. This is not, however, a book to be taken up lightly, and the discursive style does not always make for easy reference. All the same, most of the important aspects of gastrointestinal pathology are tackled with confidence and few of the sections could be bettered. While expensive, this book is lavishly illustrated and comprehensively documented. Its value as a major reference text for both clinical and pathological gastroenterologists cannot therefore be seriously doubted.

F D LEE

Basic Histopathology. A Colour Atlas and Text. 2nd ed. (Pp 252; £24.95.) Churchill Livingstone. 1991. ISBN 0-443-04237-3

The aim of this book is to introduce histopathology to medical and dental students who are covering pathology in the pre-clinical or clinical course. In many centres there is less emphasis on practical microscopic histopathology, with a higher proportion of course work on understanding the theory of mechanisms in disease. However, this book would still be a useful supplement to a less practical course in view of the well presented and concise text, illustrated with clinical examples. Over one third of the book covers basic pathological processes, and this would be the most useful part of the book for more theoretical pre-clinical course work. Subjects such as inflammation, neoplasia, atherosclerosis, and other vascular disorders are particularly well presented.

The use of photomicrographs is of most value in the section of the book covering systemic pathology. Large colour plates are used and are of excellent quality. Some of the low power views, always the most difficult to produce, are unfortunately rather blurred. All the photomicrographs are supplemented with adjacent text.

The book assumes a good knowledge of the normal histology of organs and tissues, and without this the full benefit of the book will be missed. This second edition will be a very worth while book for students, not only medical or dental, but in other disciplines needing a concise book on histopathology. I would also recommend it to junior histopathologists as an introductory text.

E A SHEFFIELD

Diagnosis and Management of Melanoma in Clinical Practice. Ed N Kirkham, D W K Cotton, R C Lallemand, J E White, R D Rosin. (Pp 190; DM 146.00.) Springer Verlag. 1992. ISBN 3-540-19717-6

The incidence of malignant melanoma is rising exponentially. It is a visible disease and therefore may be diagnosed early (even at an in situ stage) and cured by surgery. The contrast between this and the lack of effective treatment in advanced disease is stark.

This book is an informative and thoughtprovoking collection of articles from a multidisciplinary group of authors, many of whom are members of the Melanoma Study Group. This is an association of British specialists set up in the light of the success of the Scottish Melanoma Group. Many of the reviews are up to the minute. Certain chapters overlap, particularly those dealing with clinical aspects. The book is comprehensive, although a serious omission is any discussion regarding ocular melanoma. However, it fulfils its aim of "essential reading for anybody involved in the study or management of malignant melanoma".

Overall, the standard of the contributions is very high indeed. Particularly outstanding are those on histological diagnosis and of histopathological differential diagnosis. Those on familial melanoma, prognosis, surgery and isolated limb perfusion are also excellent. That on systemic treatment is thorough but makes depressing reading and serves to highlight how critical publicity and early diagnosis are. It is a pity, therefore, that the colour clinical photographs are indifferent; some of them have been published elsewhere, and show relatively advanced cases.

P A Riley writes encouragingly by presenting a stimulating chapter on prospects for new therapeutic targeting strategies for disseminated melanoma. Clinicians can all too often underestimate the psychological impact of the diseases they treat and the chapter by 